\title{
The New Face of Internet User Typology: The Case of Thailand
}

\section{Donyaprueth Krairit}

National Institute of Development Administration (NIDA), NIDA Business School, Bangkok, Thailand, donyaprueth.kra@nida.ac.th

Received 2 April 2017; received in revised form 5 October 2017; accepted 17 October 2017

\begin{abstract}
As the number of Internet users grows rapidly, the way users access the Internet and their behavior change. This study focuses on Internet user typology, which is an area that has not been recently examined. The research explores whether the Internet user typology specified in previous literature is still applicable in the present and, if not, what has changed. The results reveal that the previous way of categorizing users into several types based on their activities alone is no longer applicable. Consequently, the researcher proposed a new methodology to group users based on applications and the frequency of accessing them, coupled with the use of demographic data. The survey-based cluster analysis shows four Internet user types in Thailand. Only one group is similar to previous literature, which is the non-users. In addition, there are three new groups of users that have characteristics that are completely different from the typologies in the previous literature. The most interesting and unexpected finding is the new type of user that the researcher calls the self-satisficing group, the name of which could be related to the concept of satisficing theory in economics.
\end{abstract}

Keywords: Internet User Typology, Self-satisficing, Self-satisficing Internet Users, Categories of Internet Users, New Groups of Internet Users 


\section{Introduction}

Internet usage has increased exponentially during the past decade. This trend is not limited to Western developed countries but also applies to the rest of the world. It is therefore important for the parties involved, such as regulatory agencies, electronic commerce players and practitioners and even academicians, to understand the types of Internet users in all contexts of use so that they can treat the Internet users properly. To obtain a precise picture of Internet users, it is important to determine how many user types there are and how to access them.

Understanding Internet user behavior can be complicated. Since the exponential growth of the Internet, users are more varied and subtle in their usage. The use of modern mobile equipment, such as smartphones, also adds to the complexity of the usage. Smartphones add a new dimension of usage in that they can be taken with the users everywhere and transactions can be conducted at any time.

Since 2001, researchers have been trying to categorize Internet users into different typologies so that the ecommerce industry can treat them accordingly. The study of this area is called Internet user typology. Much research has addressed this issue and tried to categorize and name users in each group. There are at least 10 studies on Internet user typologies from 2008 to 2010 according to the compilation of Brandtzæg [3]. Most of them consider Western developed countries.

This study is among the first to explore Internet user typologies since the last major research conducted by Brandtzæg [3]. It is also among the first few studies of Internet user typology in developing countries, using Thailand as a case study.

One major difference from previous research is that during the past four years, there has been an exponential increase in Internet penetration, smartphones and Internet applications. Therefore, it can be expected that the typology of Internet users has changed and that there are many more Internet users than in the past.

The objectives of this research are therefore two-fold. The first objective is to explore whether the Internet user typology and characteristics described in prior research, mainly as compiled and proposed by Brandtzæg [3], still apply, in particular to developing countries, using Bangkok and major provincial areas of Thailand as a case study. The second objective is to explore and explain the differences or the similarities and support the findings with related theories and empirical evidence.

The major contribution of this research lies in the fact that the study finds significant differences in Internet user typography compared to previous literature. It also finds that there are differences in user behaviors, in terms of their application usage, purpose and usage frequency.

This study proposes a new way to cluster Internet users into several groups based on the new finding that one user uses several types of applications and at different frequency levels. It proposes a method to calculate actual usage of the users and uses cross-tabulation techniques to extend the findings from the demographics of the users.

In contrast with the five to eight Internet user typologies found in prior research in Western countries, the surveybased cluster analysis in Thailand shows only four Internet user types in Thailand. Only one group is similar to previous literature, which is the non-users.

In addition, there are three new groups of users that have completely different characteristics from the typologies in the previous literature. The most interesting and unexpected finding is the new type of user described as the selfsatisficing group, related to the concept of satisficing theory in economics.

\section{Internet Usage in Thailand}

Contrary to popular belief, Thailand, categorized as a developing country, has had rapid development in terms of Internet access and usage. This trend is shown in Table 1. Thai people, particularly those living in downtown or metropolitan areas, are found to be well-equipped with both Internet devices and a wide range of Internet applications. Almost half of the country's population (42.7\%) has Internet access, and the number is increasing at a two-digit growth rate almost every year. This trend is expected to continue.

To get a better picture of the high general Internet usage in Thailand, one can also look at the electronic commerce (e-commerce) as a reflection of how fast the Internet usage is growing. The value of the e-commerce market was forecast to be 2.1 trillion baht ( $\$ 58.4$ billion) in 2015 , a $3.65 \%$ raise from 2014 , as reported by the Electronic Transactions Development Agency (ETDA), a Thai governmental agency [Website 2]. 
Table 1: Thailand internet users

\begin{tabular}{|l|l|l|l|l|l|l|l|}
\hline Year & $\begin{array}{l}\text { Internet } \\
\text { Users }\end{array}$ & $\begin{array}{l}\text { Penetration } \\
\text { (\% of Pop) }\end{array}$ & $\begin{array}{l}\text { Total } \\
\text { Population }\end{array}$ & $\begin{array}{l}\text { Non-Users } \\
\text { (Internetless) }\end{array}$ & $\begin{array}{l}\text { 1Y } \\
\text { User } \\
\text { Change }\end{array}$ & $\begin{array}{l}\text { 1Y User } \\
\text { Change }\end{array}$ & $\begin{array}{l}\text { Population } \\
\text { Change }\end{array}$ \\
\hline $2016^{*}$ & $29,078,158$ & $42.70 \%$ & $68,146,609$ & $39,068,451$ & $6.20 \%$ & $1,708,982$ & $0.28 \%$ \\
\hline $2015^{*}$ & $27,369,176$ & $40.30 \%$ & $67,959,359$ & $40,590,183$ & $15.80 \%$ & $3,739,581$ & $0.34 \%$ \\
\hline 2014 & $23,629,594$ & $34.90 \%$ & $67,725,979$ & $44,096,385$ & $21.10 \%$ & $4,109,153$ & $0.41 \%$ \\
\hline 2013 & $19,520,442$ & $28.90 \%$ & $67,451,422$ & $47,930,980$ & $9.80 \%$ & $1,748,813$ & $0.43 \%$ \\
\hline 2012 & $17,771,629$ & $26.50 \%$ & $67,164,130$ & $49,392,501$ & $12.20 \%$ & $1,935,748$ & $0.39 \%$ \\
\hline 2011 & $15,835,880$ & $23.70 \%$ & $66,902,958$ & $51,067,078$ & $6 \%$ & 896,867 & $0.32 \%$ \\
\hline 2010 & $14,939,013$ & $22.40 \%$ & $66,692,024$ & $51,753,011$ & $11.70 \%$ & $1,562,826$ & $0.22 \%$ \\
\hline 2009 & $13,376,188$ & $20.10 \%$ & $66,548,197$ & $53,172,009$ & $10.60 \%$ & $1,281,695$ & $0.14 \%$ \\
\hline Source: $[$ Website 2$]$ & & & & &
\end{tabular}

Bain \& Company, through its joint research with Google, estimated that 11 million consumers conduct online purchases in Thailand. Moody's Analytics found that the increased use of electronic payments, including credit, debit and prepaid cards, added US $\$ 3.18$ billion $(0.19 \%)$ to Thailand's gross domestic product from 2011-2015, the largest weighted average increase in Asia. Half of all online purchases in the country are made through mobile devices. This trend is expected to increase as the availability of nationwide $4 \mathrm{G}$ telecommunications providers becomes widespread [site 1]. It is worth noting that these numbers are just numbers of electronic commerce, which is only a reflection of the overall Internet usage in Thailand.

The number of Internet users in Thailand has grown so fast in part because Internet players understand Thai consumers' habits, including a preference for a personalized experience through social media and websites. This has allowed them to better tailor to local customers' needs. There is an overwhelming culture of trust among Internet users in Thailand towards most applications, such as Facebook and electronic marketplaces [site 2]. Thais tend to not have much trouble with trust when it comes to Internet usage. Therefore, the Internet growth is continuing quickly [site 2].

\section{Literature Review}

When the spread of the Internet and social networks first began, several studies investigated different types of Internet users [12], [14], [17] and many more studies followed. Research has been conducted on Internet users in the U.S. [7], [13], [16], [18], [19]; in Canada [13]; and in Scandinavian countries including Norway and Sweden [15]. There are also a number of studies that focus on EU countries and others that compare the EU with the U.S. [1], [9], [10].

In addition to looking at the literature based on countries where the research was conducted, one can also group studies broadly into two groups. Studies in the first group are based on different theories, and those in the other are exploratory in nature. Most of the early studies were based on different theories and determined types of users based on the theories used. The subsequent studies were mostly exploratory studies and did not rely on any specific theories. As a consequence, the results of this latter type of studies uncovered more diverse and new types of users. The literature review will be presented based on the aforementioned groups: the first studies introduced are theorybased, and the later ones are exploratory studies.

One of the first studies that started to consider and map Internet users by patterns of use is Howard, et al [9], in 2001. The study is based on Roger's diffusion theory. It grouped users into four types, namely, netizens who are experienced users and use the Internet every day; utilitarians who are also experienced users but have less intensive usage; experimenters who have 1-3 years of experience on the Internet, and newcomers who have less than one year of experience. The study used a questionnaire survey and simple frequency analysis to group users.

The next study, also in 2001, is by Shah et al. [17]. The study is based on the theory of uses and gratifications and theory on media use. It used questionnaire survey and was among the first studies to use factor analysis in grouping users together. Based on the two theories used, the authors were able to group users into four groups, namely, social recreation, product consumption, financial management and information exchange. The meanings of each group are straightforward as their names. 
Another study was conducted in 2002 by Sheehan [18], who used the theory of privacy typologies and consumer typologies. The study was quantitative and used cluster analysis to group users. The author found four types of users, namely, unconcerned Internet users, circumspect users, wary Internet users and alarmed Internet users.

A study by DeYoung and Spence in 2004 [5] was based on the personality theory and computer attitude. It used questionnaire survey and factor analysis to categorize users. The study found seven types of users: interest, anxiety, approval, confidence, Internet transactions, entertainment and complex design preference.

Another study by Shih and Venkatesh [19], in 2004, also followed Roger's diffusion theory [19] and used questionnaire survey and regression analysis to group users. They found four groups of users, which are Internet users, specialized users, non-specialized users and limited users.

The Kozinets framework for segmenting participation in a virtual community was used by Jepson [10] in 2006 to identify groups of users. The study used questionnaires and segmented users based on the median and mean scores. Jepson found four groups of users. They are insiders, who have strong ties to other members of the community; devotees, who maintain a strong interest in consumption but have few social attachments; mingles, who maintain strong social ties while being little interested in consumption activity; and tourists, who have no ties and just drop by the community every now and then.

A later study by Ortega [15], in 2007, is also based on Roger's theory of diffusion of innovations model and the technology acceptance model (TAM) [15]. The results are based on these theories, and users are grouped as nonusers, laggards, followers and advanced users. The new type proposed without following the theories is the confused and adverse users, which represents only $2 \%$ of users and includes those who are confused about Internet services. This study used quantitative analysis and has one of the largest sample sizes of 30,336 respondents.

Another study based on a different theory is the research by Johnson and Kulpa [11] in 2007. They based their study on the theory of personality (behavior typology) and sociability. The study utilized quantitative analysis using factor analysis. The samples are limited to college students. Based on this theory, the authors categorized users into three groups, namely, sociability, which are the Internet users whose online behaviors are characterized by social orientation; utility, characterized by efficiency orientation; and reciprocity, characterized by cognitive stimulation and active involvement. The findings of this study, like [15], are limited to the theories that they are based on.

Another study by Barnes et al. [1] in 2007 was based on the theory of consumer typologies and personality constructs in psychology, extraversion and neuroticism. The study surveyed 1,011 online shoppers and used cluster analysis to group them. The results of the study are, again, within the scope that the study is based on. The authors found risk-averse doubters, open-minded shoppers and reserved information seekers, who are typically careful and reserved and have high perceived risk when shopping.

Later research in this field is mostly exploratory and does not rely much on theories. One of the first in this group is a report by Forrester [13] in 2007. The study mapped social technographics with participation in different activities. The study did not look at the types of Internet users in particular, but it was a starting point for grouping users based on their activities. It grouped users into six types, namely, creators, critics, collectors, joiners, spectators and inactives. The study was not based on any specific theories and used cluster analysis to group users.

Another study in 2007 was conducted by Horrigan [8]. He used cluster analysis techniques with no theoretical base. He found six groups of users. They are the omnivores, those who are the most active participants in the information society; the connectors, those who participate actively and use the Internet to connect with people; the lackluster veterans, those who are not passionate about information and communication technologies (ICTs); the productivity enhancers, those who get many things done by using ICTs; the mobile centrics, those who are attached to their mobile phones and applications; and the connected but hassled, those who invest in much technology but find getting connected to be a hassle.

A study by British's Office of Communication (OFCOM) [14] in 2008 looked at 39 users of social networking sites and 13 non-users. It used interviews and qualitative in-depth analysis to group Internet users and found that users can be separated into five types, namely, the alpha socializers, who are regular users but with short bursts; the attention seekers, who seek attention and comments from others; the followers, who are on the Internet to keep up with others; the faithfuls, who look for old friends on the Internet; and the functionals, who use the Internet for a particular purpose. This study is an exploratory study and groups the users based on their behaviors.

Another study was conducted by Brandtzæg and Heim in 2010 [3] and grouped users based on their patterns of use. The samples are teenagers in Norway. The authors found that, based on their usage patterns, Internet users can be grouped differently from [4]. They categorized the users into sporadics, who do not get overly involved with the Internet; lurkers, who are on the Internet to kill time; socializers, who are active in online communities; debators, who are active in getting into the discussions; and actives users, who engage in all kinds of activities. Their study is quantitative and uses cluster analysis to group users. 
Of a large body of research, one of the most comprehensive and most cited works is a study by Brandtzæg [3], who conducted an extensive review of all relevant studies during the period 2001-2010. In all, 22 studies and 5 relevant theories were reviewed in detail.

After this comprehensive review, Brandtzæg organized all of the user groups of the previous research, regardless of what they were called in each study, into several groups of the same characteristics and renamed them according to his own terms. For example, he grouped the debaters, contributors and creators user types labelled in previous studies under his term, debaters. He grouped interactors, on-off shoppers, lurkers and tourists as labelled in previous studies under his term, lurkers.

In the regrouping of user types found in previous studies, Brandtzæg defined eight groups of users. The eight groups are described in Table 2 below.

Table 2: User types according to Brandtzæg's study

\begin{tabular}{|l|l|}
\hline User types defined & Justification \\
\hline Non-users & $\begin{array}{l}\text { Non-users of the media investigated and the most common of all user types } \\
\text { in representative studies. }\end{array}$ \\
\hline Sporadics & $\begin{array}{l}\text { Identified in } 20 \text { studies. One of the most evident user types. Users that are } \\
\text { newcomers and are low-level or sporadic users of the particular media } \\
\text { studied. }\end{array}$ \\
\hline Debaters & $\begin{array}{l}\text { Bloggers and debaters in social networks. This type of user is an up and } \\
\text { coming user type because of new social media and easier tools for blogging, } \\
\text { discussion and debating. }\end{array}$ \\
\hline Entertainment users & $\begin{array}{l}\text { This type of user is identified in ten studies. Probably an up and coming user } \\
\text { type because of the high increase in gaming. }\end{array}$ \\
\hline Socializers & $\begin{array}{l}\text { Identified in nine studies. An increasing user type because of the advent of } \\
\text { social media applications. }\end{array}$ \\
\hline Lurkers & $\begin{array}{l}\text { Only identified in five studies but account for the biggest user type in social } \\
\text { media. They use the media mainly for goofing off, lurking, killing time or } \\
\text { window shopping. }\end{array}$ \\
\hline Instrumental users & $\begin{array}{l}\text { Identified in } 16 \text { studies. This is a common user type related to media in } \\
\text { general and the Internet in particular. Users that use media for utility and as } \\
\text { an information tool, both at work and in private. Not so obvious in social } \\
\text { networks. }\end{array}$ \\
\hline Advanced users & $\begin{array}{l}\text { Identified in } 20 \text { studies. Along with sporadics, this is the most common user } \\
\text { type. This type represents users that use a wide range of media frequently, } \\
\text { using the most advanced facilities compared to the rest of the user } \\
\text { population. }\end{array}$ \\
\hline
\end{tabular}

Source: [3], p. 231-253.

In addition to grouping user types together, Brandtzæg also identified the criteria for defining user types by media behavior [3]. He described his detailed user characteristics as an initial unified media-user typology, or MUT. Table 3 shows the details for each user type.

Since Brandtzæg's work, there have been no major studies on Internet user typology, but studies focus on classifying users into categories and renaming the groups as in prior research.

\section{Methodology}

This study uses one of the most robust techniques available, known as the three-pronged approach. The threepronged approach consists of, first, an extensive literature review to determine an interesting research issue and related literature. Once the research issue is identified, the conceptual research framework is proposed, and a detailed review of related literature is conducted. The second prong is the expert interviews in which a panel of experts in all aspects of the research issue is interviewed to obtain additional knowledge and insights. Then, the information from the literature review and expert interviews is combined to confirm the proposed framework, and the survey questionnaire can be drafted.

The third prong is the survey. Although the literature review and results from the expert interviews could provide reasonable hypotheses or results for the proposed research framework, it is preferable to have quantitative data that can substantiate or contrast with prior literature and expert interviews. Accordingly, the questionnaire survey is an important part of the research.

Taken together, the three-pronged approach can cross-validate the results from each prong and provide sufficient evidence to support the results derived from the research. This methodology is employed to achieve the aforementioned research objectives, which are to explore whether the Internet user typology and characteristics 
described in prior research still apply, and to explore and explain the findings with related theories and empirical evidence.

Table 3: An initial media-user typology (MUT) and the four criteria for defining types by media behavior

\begin{tabular}{|c|c|c|c|c|}
\hline User Types & Frequency of use & Variety of use & Typical activity & Typical media platform \\
\hline Non-users & No use. & No use. & None. & All. \\
\hline Sporadics & Low use. & Low variety. & $\begin{array}{l}\text { No particular activity. } \\
\text { Low interest. Less } \\
\text { experienced. }\end{array}$ & All. \\
\hline Debaters & Medium use. & Medium variety. & $\begin{array}{l}\text { Discussion and } \\
\text { information acquisition } \\
\text { and exchange. } \\
\text { Purposeful action. }\end{array}$ & $\begin{array}{l}\text { Blogs and social } \\
\text { networks. }\end{array}$ \\
\hline $\begin{array}{l}\text { Entertainment } \\
\text { users }\end{array}$ & Medium use. & Medium variety. & $\begin{array}{l}\text { Gaming or passively } \\
\text { watching videos, but } \\
\text { also advanced use, } \\
\text { such as gaming and } \\
\text { shopping. }\end{array}$ & New media in general. \\
\hline Socializers & Medium use. & Medium variety. & $\begin{array}{l}\text { Socializing, keeping in } \\
\text { touch with friends and } \\
\text { family and connecting } \\
\text { with new friends. Active } \\
\text { social life, but less } \\
\text { organized and } \\
\text { purposeful, more } \\
\text { spontaneous and } \\
\text { flexible. }\end{array}$ & Social networks. \\
\hline Lurkers & Medium use. & Low variety. & Lurking, time-killing. & $\begin{array}{l}\text { Social networks, and } \\
\text { new media in general. }\end{array}$ \\
\hline $\begin{array}{l}\text { Instrumental } \\
\text { users }\end{array}$ & Medium use. & Medium variety. & $\begin{array}{l}\text { Choose media content } \\
\text { for information } \\
\text { purposes, utility } \\
\text { oriented, often work } \\
\text { related. Low on } \\
\text { entertainment use. } \\
\text { When shopping, } \\
\text { comparing brands and } \\
\text { promotional offers. }\end{array}$ & $\begin{array}{l}\text { Internet and online } \\
\text { shopping. }\end{array}$ \\
\hline Advanced users & High use. & High variety. & $\begin{array}{l}\text { All (gaming, homepage } \\
\text { design, shopping, } \\
\text { programming, etc.). }\end{array}$ & All. \\
\hline
\end{tabular}

\subsection{Expert Interviews}

Eleven experts were interviewed in this study. Experts were selected based on their experience and background so that together they could cover as many aspects as possible. Four of them were Internet marketing managers or ecommerce entrepreneurs. This group of experts provided the researcher with views on how they perceived the market and their customer groups. Three of them were academicians whose views could confirm whether the conceptual ideas of this research were valid and provide an academic perspective. Two experts were Internet users themselves, with at least ten years of experience with the Internet. These users were selected because of their long association with the Internet and experience in seeing the Internet grow over the past ten years. The last two experts were experienced users of the Internet with six and seven years of experience.

The interviews with the experts were conducted individually and lasted approximately one hour for each person. The interview questions were semi-structured and asked in different orders with each person to ensure the least bias possible. The interviews were qualitative in nature. They were recorded and transcribed into written scripts and encoded and counted to find the common thread or keywords among all interviewees. The process of data analysis is to assemble or reconstruct the data in a meaningful or comprehensible manner, in a way that is transparent, rigorous and thorough, while remaining true to participants' accounts. The results of these processes were then translated back into the answers to the original questions. 


\subsection{Questionnaire Survey}

The data used in this study are primary data. The self-administered questionnaires were distributed to 682 people to get the acceptable rate of 400 surveys returned, representing a $58.65 \%$ response rate. A stratified random sampling technique was used to reflect the pattern of the population.

This study focuses on individuals aged 21-50 years old. The unit of analysis is at the individual level.

The questionnaire consists of two parts. The first part covers the demographics of the respondents. The second part consists of questions about the usage and frequency of use of several Internet applications and the respondents' behaviors on each application used. The frequency of use is divided into five categories, namely, more than once a day, every day, 4-6 times a week, 1-3 times a week and never.

The nine Internet applications covered in the questionnaire included Internet banking, Facebook, YouTube, social messaging services including Line and whatsapp, general Internet usage via direct website access or Google, gaming, Instagram, blogging and advanced programming. Questions on these applications covered activity preference, variety of use and platform dimensions as mentioned in Brandtzæg's framework [2].

The respondents were asked to answer (Yes/No) whether they used the abovementioned applications. In addition, if they used a particular application, they had to describe how often they used it, using a Likert scale of 1-5 according to the frequency. The frequency of use was divided into four levels, namely: every day or more than once a day was considered high usage, 4-6 times a week was considered medium usage, 1-3 times a week was considered low usage, and never was considered no usage.

\subsection{Statistical Analysis and Exit Interviews}

The data from the survey were analyzed using SPSS software version 21 . The following Table 4 shows the demographics of the respondents.

Table 4: Demographics of the respondents

\begin{tabular}{|c|c|c|c|}
\hline & Persons & Percent & Cumulative Percent \\
\hline \multicolumn{4}{|l|}{ Gender } \\
\hline Male & 200 & 50.0 & 50.0 \\
\hline Female & 200 & 50.0 & 100.0 \\
\hline \multicolumn{4}{|l|}{ Age } \\
\hline $21-25$ & 65 & 16.3 & 16.3 \\
\hline $26-30$ & 75 & 18.8 & 35.0 \\
\hline $31-35$ & 84 & 21.0 & 56.0 \\
\hline $36-40$ & 80 & 20.0 & 76.0 \\
\hline $41-45$ & 51 & 12.8 & 88.8 \\
\hline $46-50$ & 45 & 12.0 & 100.0 \\
\hline \multicolumn{4}{|l|}{ Income Level } \\
\hline Less than 10,000 THB & 29 & 7.2 & 7.2 \\
\hline $10,001-20,000$ THB & 108 & 27.0 & 34.3 \\
\hline $20,001-30,000$ THB & 114 & 28.5 & 62.7 \\
\hline $30,001-40,000$ THB & 80 & 20.0 & 82.8 \\
\hline $40,001-50,000$ THB & 52 & 13.0 & 95.8 \\
\hline $50,001-60,000$ THB & 15 & 3.8 & 99.5 \\
\hline $60,001-70,000$ THB & 2 & .5 & 100.0 \\
\hline \multicolumn{4}{|l|}{ Education Level } \\
\hline Primary School & 16 & 4.0 & 4.0 \\
\hline High School & 113 & 28.2 & 32.3 \\
\hline Diploma & 81 & 20.3 & 52.5 \\
\hline Undergraduate & 186 & 46.5 & 99.0 \\
\hline Graduate & 4 & 1.0 & 100.0 \\
\hline
\end{tabular}

The first task to prepare data for the analysis is to separate the non-user group from the total sample. There were 40 non-Internet users, accounting for $10 \%$ of the total sample. This group was taken out and labelled as non-users. 
The remaining 360 samples are the subject of the analysis conducted by SPSS software. Cluster analysis was conducted based on the Internet activities of the users. Cluster analysis is a robust technique to group together samples with the same characteristics.

After that, the first cluster analysis was performed on the usage data for all applications. The results were unclear, and no conclusions could be drawn because the results showed more than seven clusters with mixed usage and frequency of use. In addition, the clusters were not very different from each other because of the high number of clusters that resulted from the analysis. Therefore, no common themes could be drawn. Then, the second cluster analysis was performed for each application. The results were the same as the first round, inconclusive and different for each application. Again, no common themes or types of users could be drawn from this round of analysis.

The researcher then made a third round of cluster analysis. In this round, the researcher summed the number of applications that each user uses, termed the actual number of applications used. Then, the frequencies of use of each application for each user were summed together, termed the total frequency of usage. As the final step, the two numbers were multiplied together to obtain what is termed the actual usage, which is a composite measure of the number of applications used and the frequency of usage. The actual usage is the number that is subsequently used in the cluster analysis.

Following past research, the K-mean cluster analysis was first conducted with the data on frequency of Internet usage for any application, where $\mathrm{K}$ was the number of clusters mentioned in previous research. The first run was conducted where $K=7$ as indicated in the literature. The second run was conducted with $K=3$, the third run with $K=4$, and the last run with $\mathrm{K}=2$.

Exit interviews were also conducted with approximately $50 \%$ of the respondents after they completed the questionnaire to ask their opinions and reasons for choosing applications; this helped in categorizing the users.

\section{Results}

This section presents the results from the expert interviews and from the statistical analysis. The results of the expert interviews are explained according to the users' types. The results from the statistical analysis are explained and grouped to show the detail of the statistics.

\subsection{Results of the Expert Interviews}

The results from the expert interviews are quite diverse, which is understandable, when one is asked how one would categorize Internet users. The questions that were asked were made to be easily understandable, and enough time was provided so that the experts could formulate reasonable answers. The experts were allowed to provide their insights in more than one way. For example, they did not have to limit their answers to only one criterion.

At first, some experts did not have a clear understanding of the concept of an Internet user typology. However, when explained, almost all of them started by mentioning social networks and subjective norms. They believed that subjective norms play important roles in grouping Internet users together. All of the experts mentioned two types of Internet users at first, namely those who do not use the Internet or who the literature frequently mentions as nonusers or laggards, and those who are on the Internet. Thais are quite modest. Most of the experts showed uncertainty at first. One expert said,

I am not sure what typology means. If you mean the types of Internet users, there are definitely two main groups, namely, the non-users (coded as non-users in the analysis) and the users group. I do not know if that is enough for you. You can also think of other ways to group the Internet users, but you have to remember that there are non-users, as well.

When asked further to categorize only the users who are on the Internet, all of them believed that there are shoppers and social network users, particularly socializers. Seven out of 11 believed that there are purposeful users that use the Internet for specific jobs or purposes. One expert noted the following:

When I think about different types of Internet users, most of the time, I think of people on social networks like Facebook talking and socializing with each other (coded as Socializers in the analysis). After all, that is where most Internet users are most of the time. I think Thai people like to chit-chat and show off what they experience in their lives. That is why we see feeds about food they eat and activities that they do during the day.

The next thing I think about is I think of Internet users as shoppers. They know what they are looking for and whether what is offered to them is suitable to them or not. (Coded as purposeful users in the analysis)

Another expert also had the same opinions. 
I think most Thais like to be online. Whenever they cannot think of the meaning of something or they want to look for something, Google always is the best place that they decide to go (coded as purposeful users in the analysis). They go on the Internet to look for something or shopping. Thais also socialize a lot on social networks. I cannot even read all the feeds on my Facebook and I cannot even remember which Facebook I checked the Like button. The information is just overwhelming. (Coded as socializers in the analysis.)

Three came up with the term entertainers. As one expert mentioned:

Thai people love to have fun in their lives. They do not want to deal with serious stuff. Most of them, I think, think that they have enough stress from their work. So, they want to have fun on the Internet. That is why most of them are on social networks. Most of the status on the feeds are also about food, funny stuff, their pets, and so on. Mostly, light stuff in their lives. It is one way of entertainment for them, besides watching television and travel. (Coded as entertainers in the analysis.)

Four out of 11 thought that there are also gamers. In fact, there are more than 15 million gamers in Thailand. One expert who has been on the Internet for more than ten years believed that gamers are one type of Internet users.

I have been on the Internet for more than ten years. One thing that I have seen being developed continuously is the games. Now that everyone can be on the Internet, I am sure there will be a lot of people out there who want to be connected through the online games. I am pretty certain that this group of online gamers will grow in the future. At least, I am one of them. (Coded as gamers in the analysis.)

Only three out of 11 mentioned advanced users who do programming and advanced blogging on the Internet. One of the experts happened to be a blogger. He thinks that programmers and bloggers comprise one type of Internet users. As he noted,

I am a blogger (coded as advanced users in the analysis), and I do some script programming on the Internet. We have a large community of us on the Internet. I think general Thais are not very technical-oriented. But some are. And they are serious about it. I blog technical news and write articles on new technologies. I have a number of followers of my blogs. Most of them just read. They do not blog or program by themselves.

Interestingly, none of the experts mentioned the users of social messaging services, such as Line and whatsapp, as one of the major user types. Most of them thought only about users on Internet applications, forgetting that most Thai users communicate through the social messaging networks on their mobile phones. This shows that they do not perceive social messaging services as an application of social networks. Accordingly, one of the most widespread applications in Thailand was overlooked. The summary of the interviews is presented in Table 5.

Table 5: Summary of the expert interviews

\begin{tabular}{|l|l|l|l|l|l|l|}
\hline $\begin{array}{l}\text { Expert } \\
\text { number } \\
\text { users }\end{array}$ & Socializers & Entertainers & $\begin{array}{l}\text { Instrumental } \\
\text { users } \\
\text { (Purposeful } \\
\text { users) }\end{array}$ & Gamers & $\begin{array}{l}\text { Advanced } \\
\text { users }\end{array}$ \\
\hline 1 & $\sqrt{ }$ & $\sqrt{ }$ & & $\sqrt{ }$ & & \\
\hline 2 & $\sqrt{ }$ & $\sqrt{ }$ & $\sqrt{ }$ & $\sqrt{ }$ & & \\
\hline 3 & $\sqrt{ }$ & $\sqrt{ }$ & & & $\sqrt{ }$ & \\
\hline 4 & $\sqrt{ }$ & $\sqrt{ }$ & & & $\sqrt{ }$ & $\sqrt{ }$ \\
\hline 5 & $\sqrt{ }$ & $\sqrt{ }$ & & $\sqrt{ }$ & $\sqrt{ }$ & \\
\hline 6 & $\sqrt{ }$ & $\sqrt{ }$ & & $\sqrt{ }$ & $\sqrt{ }$ & \\
\hline 7 & $\sqrt{ }$ & $\sqrt{ }$ & $\sqrt{ }$ & & & \\
\hline 8 & $\sqrt{ }$ & $\sqrt{ }$ & $\sqrt{ }$ & $\sqrt{ }$ & & \\
\hline 9 & $\sqrt{ }$ & $\sqrt{ }$ & & $\sqrt{ }$ & & \\
\hline 10 & $\sqrt{ }$ & $\sqrt{ }$ & & $\sqrt{ }$ & & \\
\hline 11 & &
\end{tabular}

\subsection{Results from the Statistical Analysis}

For the $10 \%$ of those surveyed in the non-user group, the most common reason for their non-use is that they do not know how to use the Internet. The second most common reason is that they deem the Internet as not necessary for their lives. This is considered the first group of users in this study and is separated from the remaining $90 \%$ of those surveyed who are Internet users.

For the remaining $90 \%$ of Internet users, the researcher explored the data further by conducting cluster analysis. Four rounds of K-mean cluster analysis were performed. After comparing the results of all four K-mean analyses (with $\mathrm{K}=2,3,4$, and 7 ), the most interpretable and meaningful cluster is found when $\mathrm{K}=3$. This means that the remaining users can be explained in three clusters. The final cluster center of cluster 1 is at 39.23 , that of cluster 2 is at 125.69 , and that of cluster 3 is at 226.90 . 
Subsequently, the two-step cluster technique is used to confirm the number of clusters obtained from the K-mean cluster analysis. The two-step cluster analysis also suggests three clusters as a result for grouping Internet users, excluding the non-users, who are already counted as one group. The model quality is at 0.70 , which is well above the threshold value of 0.5 and considered acceptable for use of the clusters obtained. See Table 6.

Table 6: Final cluster centers

\begin{tabular}{|l|l|l|l|}
\hline \multirow{2}{*}{} & \multicolumn{3}{|l|}{ Cluster } \\
\cline { 2 - 4 } & 1 & 2 & 3 \\
\hline Actual usage & 39.23 & 125.69 & 226.90 \\
\hline
\end{tabular}

The researcher then performed the third analysis to verify that the $K$ value of 3 is the most appropriate number for grouping Internet users by conducting post hoc ANOVA on the members of each cluster to determine that each cluster is really different and can be separated statistically. The post hoc ANOVA assumes Bonferroni equal variances.

Table 7: Analysis of Variance (called ANOVA) result of $\mathrm{K}$ value where $\mathrm{K}$ equals three

\begin{tabular}{|l|l|l|l|l|}
\hline \multirow{2}{*}{ (I) Cluster Number of Case } & $\begin{array}{l}\text { (J) Cluster Number of } \\
\text { Case }\end{array}$ & $\begin{array}{l}\text { Mean Difference } \\
(\mathrm{I}-\mathrm{J})\end{array}$ & Std. Error & Sig. \\
\hline 1 & 2 & $-86.46306^{*}$ & 3.18745 & .000 \\
\cline { 2 - 5 } & 3 & $-187.67433^{*}$ & 3.36626 & .000 \\
\hline 2 & 1 & $86.46306^{*}$ & 3.18745 & .000 \\
\hline \multirow{2}{*}{3} & 3 & $-101.21126^{*}$ & 3.62649 & .000 \\
\hline & 1 & $187.67433^{*}$ & 3.36626 & .000 \\
\cline { 2 - 5 } & 2 & $101.21126^{*}$ & 3.62649 & .000 \\
\hline
\end{tabular}

It can be seen from Table 7 that members in all three clusters are statistically different and that each cluster is statistically different from the others. The differences (P-value) are significant at the 0.00 confidence level. After all three tests, it can be concluded that the $\mathrm{K}$ value of 3 is the most appropriate value to use for clustering.

The next analysis to be performed is the number of cases in each cluster. The numbers of cases in each cluster are as follows: 158 cases in cluster 1 , accounting for $43.89 \%$ of the sample; 110 cases in cluster 2 , accounting for $30.56 \%$ of the sample; and 92 cases in cluster 3 , accounting for $25.55 \%$ of the sample. See Table 8.

Table 8: Number of cases in each cluster

\begin{tabular}{|l|l|l|}
\hline Cluster 1 & 158 & $43.89 \%$ \\
\hline Cluster 2 & 110 & $30.56 \%$ \\
\hline Cluster 3 & 92 & $25.55 \%$ \\
\hline Total & 360 & $100.00 \%$ \\
\hline
\end{tabular}

Based on the three new clusters that are found from the analysis, the cross-tabulation technique is used to explore the relationship between the actual number of applications used and the frequency of usage and the demographics of the users.

The first statistical analysis conducted is cross-tabulating the clusters with the actual number of applications that users in each cluster use. See Table 9.

Table 9: Cross-tabulation of clusters with actual number of applications used

\begin{tabular}{|l|l|l|l|l|}
\hline \multirow{2}{*}{$\begin{array}{l}\text { Actual number of } \\
\text { applications used }\end{array}$} & \% within cluster number of cases & Total \\
\cline { 2 - 5 } & Cluster 1 & Cluster 2 & Cluster 3 & \\
\hline 2 & $21.5 \%$ & $0.0 \%$ & $0.0 \%$ & $9.4 \%$ \\
\hline 3 & $15.2 \%$ & $0.0 \%$ & $0.0 \%$ & $6.7 \%$ \\
\hline 4 & $24.7 \%$ & $0.0 \%$ & $0.0 \%$ & $10.6 \%$ \\
\hline 5 & $29.7 \%$ & $0.0 \%$ & $0.0 \%$ & $13.1 \%$ \\
\hline 6 & $8.9 \%$ & $30.9 \%$ & $0.0 \%$ & $13.3 \%$ \\
\hline 7 & $0.0 \%$ & $43.6 \%$ & $0.0 \%$ & $13.3 \%$ \\
\hline 8 & $0.0 \%$ & $23.6 \%$ & $18.5 \%$ & $11.9 \%$ \\
\hline 9 & $0.0 \%$ & $1.8 \%$ & $81.5 \%$ & $21.4 \%$ \\
\hline$\%$ of Total & $100.0 \%$ & $100.0 \%$ & $100.0 \%$ & $100 \%$ \\
\hline
\end{tabular}


The results of the cross-tabulation, show that $91.1 \%$ of users in Cluster 1 use 2 to 5 applications; there is no one that uses more than six applications. For Cluster 2, 98.1\% of all users are quite active and use 6 to 8 applications. In the last cluster, $81.5 \%$ of all users use all nine applications; Cluster 3 is comparatively the most active group.

The second statistical analysis is to cross-tabulate the clusters with the sum of the frequency of use for all applications. The result is shown in Table 9.

For each application of the total nine applications in the survey, 1 means access more than once per day, 2 means access once a day, 3 means 4-6 times per week, 4 means 1-3 times per week, and 99 means never. For all nine applications, the minimum number is 1 , which indicates accessing one application but more than once a day. The maximum number is $4^{*} 9$ applications (as we do not count those who never use any applications at this stage), which equals 36, meaning the users use all applications at a frequency of 1-3 times per week. Therefore, the smaller the number, the more frequently the users use the applications. Table 10 shows the cross tabulation of clusters with the sum of frequency of use for all applications.

Table 10: Cross-tabulation of clusters with the sum of the frequency of use for all applications

\begin{tabular}{|l|l|l|l|l|l|}
\hline \multirow{5}{*}{\begin{tabular}{l} 
Sum of frequency of use for all \\
\cline { 2 - 6 } applications
\end{tabular}} & \multicolumn{3}{l|}{ Cluster Number } \\
\cline { 2 - 7 } & 2.00 & 2 & 0 & 0 & 2 \\
\hline 3.00 & 4 & 0 & 0 & 4 \\
\hline 4.00 & 21 & 0 & 0 & 21 \\
\hline 5.00 & 6 & 0 & 0 & 6 \\
\hline 6.00 & 6 & 0 & 0 & 6 \\
\hline 7.00 & 9 & 0 & 0 & 9 \\
\hline 8.00 & 18 & 0 & 0 & 18 \\
\hline 9.00 & 15 & 0 & 0 & 15 \\
\hline 10.00 & 18 & 0 & 0 & 18 \\
\hline 11.00 & 15 & 0 & 0 & 15 \\
\hline 12.00 & 16 & 1 & 0 & 17 \\
\hline 13.00 & 9 & 4 & 0 & 13 \\
\hline 14.00 & 11 & 6 & 0 & 17 \\
\hline 15.00 & 5 & 13 & 0 & 18 \\
\hline 16.00 & 3 & 13 & 0 & 16 \\
\hline 17.00 & 0 & 14 & 0 & 14 \\
\hline 18.00 & 0 & 8 & 0 & 8 \\
\hline 19.00 & 0 & 16 & 0 & 16 \\
\hline 20.00 & 0 & 16 & 2 & 18 \\
\hline 21.00 & 0 & 7 & 1 & 8 \\
\hline 22.00 & 0 & 8 & 5 & 13 \\
\hline 23.00 & 0 & 2 & 14 & 16 \\
\hline 24.00 & 0 & 1 & 11 & 12 \\
\hline 25.00 & 0 & 1 & 14 & 15 \\
\hline 26.00 & 0 & 0 & 11 & 11 \\
\hline 27.00 & 0 & 0 & 13 & 13 \\
\hline 28.00 & 0 & 0 & 7 & 7 \\
\hline 29.00 & 0 & 0 & 1 & 1 \\
\hline 30.00 & 0 & 0 & 8 & 8 \\
\hline 31.00 & 0 & 0 & 4 & 4 \\
\hline 33.00 & 0 & 0 & 1 & 1 \\
\hline
\end{tabular}

Because it is unwieldy to work with the table showing all users' frequencies of use, as shown in Table 10, the calculation is made based on the findings from the cross-tabulation. In Cluster 1, 95\% of all users have a sum of frequency of use ranging from 1-14, meaning that they access the applications they choose quite frequently. Assuming that they access the maximum possible number of applications, which is 9 , with the lowest frequency in their range, which is 14 , then the average sum of frequency of use is 14 divided by 9 , or 1.55 . This means that the 
users in cluster 1 are very active in accessing the applications, on average ranging from more than once per day to once a day. The preferred applications that the users access may differ among users.

For Cluster $2,86.3 \%$ of all users have a sum of frequency of use ranging from 15-22, meaning they access the applications they choose quite frequently. Assuming that they access the maximum possible number of applications, which is 9 , with the lowest frequency in their range, which is 22 , then the average sum of frequency of use is 22 divided by 9 , or 2.44 . This means that the users in cluster 2 access the applications on average ranging from once a day to 4-6 times per week.

For Cluster 3, $91.3 \%$ of all users have a sum of frequency of use ranging from 23-33, meaning they do not access the applications as frequently as the other two groups. Assuming that they access the maximum possible number of applications, which is 9 , with the lowest frequency in their range, which is 33 , then the average sum of frequency of use is 33 divided by 9 , or 3.67 . This means that the users in Cluster 3 access the applications on average approximately 1-3 times per week.

Based on the two analyses above, some clear characteristics of each cluster based on the number of applications used and the frequency of usage appear as follows:

- Cluster 1: Users use 2 to 5 applications but access them very often. The average frequency of usage ranges from more than once per day to once a day.

- Cluster 2: Users use 6 to 8 applications and access them on average from once a day to 4-6 times per week.

- $\quad$ Cluster 3: Extensive users who use all nine applications but access them rarely. The average frequency of access is 1-3 times per week.

The objective of the third and subsequent analysis is to extend the findings from the mere behavior of the Internet users to linking the behavior with the demographics of the users. Accordingly, the third analysis is the crosstabulation of clusters with age range. See Table 11.

Table 11: Cross-tabulation of clusters with age range

\begin{tabular}{|l|l|l|l|l|}
\hline \multirow{2}{*}{$\begin{array}{l}\text { Age Range (years } \\
\text { old) }\end{array}$} & \% within cluster number of cases & Total \\
\cline { 2 - 5 } & Cluster 1 & Cluster 2 & Cluster 3 & \\
\hline $21-25$ & $7.6 \%$ & $26.4 \%$ & $20.7 \%$ & $16.7 \%$ \\
\hline $26-30$ & $15.2 \%$ & $24.5 \%$ & $16.3 \%$ & $18.3 \%$ \\
\hline $31-35$ & $18.4 \%$ & $24.5 \%$ & $21.7 \%$ & $21.1 \%$ \\
\hline $36-40$ & $25.3 \%$ & $15.5 \%$ & $14.1 \%$ & $19.4 \%$ \\
\hline $41-45$ & $15.8 \%$ & $4.5 \%$ & $18.5 \%$ & $13.1 \%$ \\
\hline $46-50$ & $17.7 \%$ & $4.5 \%$ & $8.7 \%$ & $11.4 \%$ \\
\hline$\%$ of Total & $100.0 \%$ & $100 \%$ & $100 \%$ & $100 \%$ \\
\hline
\end{tabular}

In Cluster $1,77.2 \%$ of all users are 31-50 years old and therefore are considered the working group. In Cluster 2, $75.4 \%$ of all users are 21-35 years old. They are young people and people in their first jobs. However, in Cluster 3, users are in their early 20 s, early 30 s, and early 40 s. This group is difficult to classify, as the age distribution does not follow any pattern. Therefore, age might not be a good indicator to describe Cluster 3 .

The next analysis is the cross-tabulation between gender and clusters. See Table 12.

Table 12: Cross-tabulation of clusters with gender

\begin{tabular}{|l|l|l|l|l|}
\hline \multirow{2}{*}{ Gender } & \% within cluster number of cases & Total \\
\cline { 2 - 5 } & Cluster 1 & Cluster 2 & Cluster 3 & \\
\hline Male & $58.2 \%$ & $60.9 \%$ & $20.7 \%$ & $49.4 \%$ \\
\hline Female & $41.8 \%$ & $39.1 \%$ & $79.3 \%$ & $50.6 \%$ \\
\hline$\%$ of Total & $100.0 \%$ & $100 \%$ & $100 \%$ & $100 \%$ \\
\hline
\end{tabular}

The results of the cross-tabulation show that in Cluster 1 , there is a close proportion of male and female users. In Cluster 2, users are mostly men, representing $60.9 \%$ of the total. In Cluster 3 , however, most of the members are women, with the number of women being almost four times the number of men.

The next analysis is the cross-tabulation between income levels and clusters. See Table 13. 
Table 13: Cross-tabulation of clusters with income levels

\begin{tabular}{|l|l|l|l|l|}
\hline \multirow{2}{*}{$\begin{array}{l}\text { Income levels } \\
\text { (Baht) }\end{array}$} & \multicolumn{2}{|l|}{$\%$ within cluster number of cases } & Total \\
\cline { 2 - 5 } & Cluster 1 & Cluster 2 & Cluster 3 & \\
\hline$<10,000$ & $8.2 \%$ & $10.9 \%$ & $0.0 \%$ & $6.9 \%$ \\
\hline $10,001-20,000$ & $31.0 \%$ & $24.5 \%$ & $22.8 \%$ & $26.9 \%$ \\
\hline $20,001-30,000$ & $28.5 \%$ & $33.6 \%$ & $25.0 \%$ & $29.2 \%$ \\
\hline $30,001-40,000$ & $17.1 \%$ & $20.0 \%$ & $22.8 \%$ & $19.4 \%$ \\
\hline $40,001-50,000$ & $10.1 \%$ & $7.3 \%$ & $25.0 \%$ & $13.1 \%$ \\
\hline $50,0001-60,000$ & $5.1 \%$ & $2.7 \%$ & $3.3 \%$ & $3.9 \%$ \\
\hline $60,001-70,000$ & $0.0 \%$ & $0.9 \%$ & $1.1 \%$ & $0.6 \%$ \\
\hline$\%$ of Total & $100.0 \%$ & $100 \%$ & $100 \%$ & $100 \%$ \\
\hline
\end{tabular}

In Cluster 1, most users have income ranging from 10,001-40,000 Thai baht, with the highest percentage earning $10,001-20,000$. One observation is that no one has an income of more than 60,000 Thai baht, which is higher than average income. In Cluster 2, most users have income ranging from less than 10,000-40,000 Thai baht, with the highest percentage earning 20,001-30,000 Thai baht. In Cluster 3, most users have income higher than users in other groups, with the highest percentage in the range of $40,001-50,000$ Thai baht. The range is from $20,001-70,000$ baht. One observation is that no one receives income lower than 10,000 Thai baht.

The last analysis is between education levels and clusters. See Table 14.

Table 14: Cross-tabulation of clusters with education levels

\begin{tabular}{|l|l|l|l|l|}
\hline \multirow{2}{*}{ Highest education levels } & \multicolumn{3}{|l|}{$\%$ within cluster number of cases } & Total \\
\cline { 2 - 5 } & Cluster 1 & Cluster 2 & Cluster 3 & \\
\hline Primary School & $8.9 \%$ & $0.0 \%$ & $1.1 \%$ & $4.2 \%$ \\
\hline Senior High School & $42.4 \%$ & $22.7 \%$ & $14.1 \%$ & $29.2 \%$ \\
\hline Diploma & $17.7 \%$ & $13.6 \%$ & $31.5 \%$ & $20.0 \%$ \\
\hline Undergraduate & $30.4 \%$ & $61.8 \%$ & $53.3 \%$ & $45.8 \%$ \\
\hline Graduate or higher & $0.6 \%$ & $1.8 \%$ & $0.0 \%$ & $0.8 \%$ \\
\hline$\%$ of Total & $100.0 \%$ & $100 \%$ & $100 \%$ & $100 \%$ \\
\hline
\end{tabular}

For all clusters, the most common ranges of education are from senior high school to the undergraduate level. The highest percentage of users in Cluster 1 have a senior high school level of education. In Clusters 2 and 3 , the highest percentage of users have an undergraduate level of education.

When combined with the analysis of the income, it can be seen that there is compatibility between the highest education level and the income received.

When the results of all of the analyses are taken together, certain patterns emerge. For the remaining $90 \%$ of the sample who use the Internet, three groups were found. The first cluster is the largest group, accounting for $43.89 \%$ of the sample of users. This group uses 2-5 applications very often, more than once per day. Users' ages range from 31-50 years old. They are the working group. There are equal male and female users, and their average income tends to be low, as the highest percentage of users have income from 10,001-40,000 Thai baht. They also tend to have the lowest education levels of all the user groups, with the highest percentage of education at the primary school level, followed closely by undergraduate level.

The second cluster is the second largest group, accounting for $30.56 \%$ of the sample of users. This group uses $6-8$ applications at least 4-6 times a week (almost every day) up to every day. They age from 21-35 years old and are students and people in their first jobs. Men are twice as represented as women, and the average income ranges from less than 10,000 to 40,000 Thai baht. The income range is quite extensive for this group. Users have average education levels, with the highest percentage having education at the undergraduate level.

The last cluster accounts for $25.55 \%$ of the sample of users. This group uses all nine applications but with the lowest frequency of all the groups at 1-3 times a week. There is no pattern in their ages. In contrast to the second group, in this group, there are four times as many women as men, with average income from 20,001 to 70,000 Thai baht. The income range is the highest among all four groups. Users have average education levels, with the highest percentage having education at the undergraduate level.

At this stage, the analysis is extended by examining the applications that the respondents use to explore whether the groups can be categorized by usage purpose as done in the previous literature.

The analysis of the applications used reveals several interesting findings. All respondents who are not non-users use at least two applications, which are the Facebook and Line applications. Two applications are the minimum number for every user. In addition, the top five applications for overall users in order of percentage from high to low are first 
Facebook (100\%) and Line (100\%), second YouTube without any downloading activities (83.6\%), third Google or accessing the Internet directly $(67.8 \%)$, fourth YouTube with downloading activities (64.4\%), and fifth Internet banking (63.9\%).

What is more interesting is that when the order of applications in each cluster is analyzed, the results of application ranking remain the same for the average user in every cluster. The fact that users in each cluster choose and rank the same applications and have the same activities shows that users in each cluster cannot be named or grouped by the purpose or types of applications they use, the way they were categorized and named in the previous literature. A new way to categorize the users is therefore needed.

\section{Discussion}

After the conduction of a case study on Thailand, contrary to previous literature where users could be categorized by their usage activities, current Thai users use several applications and conduct a variety of activities at different frequency levels. This trend is the same in all clusters of Thai users. There are no longer users that use the Internet for one clear purpose or one particular application. In all clusters, Thai users' activities in the top five applications are a mix of what the previous literature called socializers, lurkers, entertainers and instrumental users. However, the researcher did not find that many Thais are debaters or advanced users. Advanced usage such as blogging and programming is the least common in Thailand among the nine applications investigated.

Therefore, in Thailand which is the case study, using the types or purposes of activities in each application to cluster types of Internet users as in the past is no longer applicable in the current situation. The research results, coupled with the results from expert interviews, show that Thai users are using more than one application at a time, and all three user clusters show a mixture of different types of users. This pattern is consistent with the results from expert interviews in that the experts were able to identify certain types of Thai users even though not all were listed in the previous literature.

Based on the exit interviews with some users, it is found that their behaviors are not based on any logical reasoning or timing. They use these applications because they feel like they want to use them, and they do not care about other applications because they feel that the applications they use are enough to respond to their needs. After further review of the literature on several related theories, it is apparent that their behavior follows what is called satisficing in economic theory.

In economics, the term satisficing refers to a combination of satisfy and suffice introduced by Herbert A. Simon (1956) [20]. Simon used satisficing to explain the behavior of decision makers under circumstances in which an optimal solution cannot be determined. He maintained that many natural problems are characterized by computational intractability or a lack of information, both of which preclude the use of mathematical optimization procedures. Satisficing users examine alternatives until a practical solution with an adequate level of acceptability is found and stop the search there instead of looking for the best possible or optimum solution.

As a result of the analyses, all three user clusters can be considered to represent a self-satisficing group. This is because the users in this group are satisfied with what they have and are not eager to find or use other applications outside of their interest. Their interests and frequencies of usage depend on what they think is suitable and sufficient for them.

With all of the information and analyzed data in hand, the patterns found are examined further with the aim of naming the four groups.

The first group is consistent with the previous literature. It is the smallest group. These respondents are what the previous literature called the laggards or the non-users. Persons in this group do not have access to the Internet, or if they do have access, they are not interested in using such connectivity. In this study, they accounted for $10 \%$ of the sample. This group, while having many of the same characteristics as in the previous literature, accounts for a much smaller percentage in this case.

The second, third and fourth groups are taken together and called the self-satisficing group in which there are three sub-groups.

Based on their behavior, the second group, which is the largest group, is labelled the always online and focused group. Users in this group, as shown in the results section, use 2-5 applications of their choice and access these applications more than once a day, meaning that they are online most of the time. Further analysis shows that most of them accept that accessing certain applications has become a regular, everyday activity for them. However, they only use a limited number of applications, so they are quite focused in their use.

The third group is labelled the often online and extensive group. This group of users uses 6-8 applications, which is quite extensive. Their access to these applications is once a day to 4-6 times a week, which means that some applications are accessed every day. For other applications, access is mostly every other day. 
The fourth group is labelled the rarely online but try-it-all group. This group is the most advanced, and users use all nine applications and are willing to try new applications. However, they access the applications only 1-3 times per week, meaning that they are not always online and neither are they addicted to these applications. This is in contrast to the previous literature, which stated that the advanced users access applications very often.

The four groups are shown in the following Table 15.

Table 15: Four groups of Internet users

\begin{tabular}{|c|c|c|c|c|}
\hline & & \multicolumn{3}{|l|}{ Self-satisficing group } \\
\hline & Group 1 & Group 2 & Group 3 & Group 4 \\
\hline & Non-users & $\begin{array}{l}\text { The always-online } \\
\text { and focused group }\end{array}$ & $\begin{array}{l}\text { The often-online and } \\
\text { extensive group }\end{array}$ & $\begin{array}{l}\text { The rarely-online } \\
\text { but try-it-all group }\end{array}$ \\
\hline $\begin{array}{l}\text { Number of } \\
\text { applications used }\end{array}$ & 0 & $2-5$ & $6-8$ & 9 \\
\hline $\begin{array}{l}\text { Frequency of } \\
\text { accessing } \\
\text { applications }\end{array}$ & 0 & $\begin{array}{l}\text { More than once a } \\
\text { day, always online }\end{array}$ & $\begin{array}{l}\text { Once a day to } 4-6 \\
\text { times per week }\end{array}$ & 1-3 times per week \\
\hline Gender & $\begin{array}{l}\text { Male and female } \\
\text { almost equal }\end{array}$ & $\begin{array}{l}\text { Male and female } \\
\text { almost equal }\end{array}$ & $\begin{array}{l}\text { Male dominated } \\
\text { group }\end{array}$ & $\begin{array}{l}\text { Female dominated } \\
\text { group }\end{array}$ \\
\hline Income & $\begin{array}{l}\text { Lower than } \\
\text { average to } \\
\text { average }\end{array}$ & $\begin{array}{l}\text { Lower than average } \\
\text { to average }\end{array}$ & average & $\begin{array}{l}\text { Average to higher } \\
\text { than average }\end{array}$ \\
\hline Age & $41-50$ years old & $\begin{array}{l}31-50 \text { years old. } \\
\text { Working group }\end{array}$ & $\begin{array}{l}21-35 \text { years old. } \\
\text { Students and first } \\
\text { jobbers. }\end{array}$ & $\begin{array}{l}\text { Cannot identify } \\
\text { patterns }\end{array}$ \\
\hline
\end{tabular}

From the above summary, it can be seen that Internet user typology has changed from the previous literature, except for the non-user group. The fact that there are many more applications available online has pushed us to re-think the way Internet users are categorized. The major criteria for categorization have changed from the activities and purposes of using applications to the number of applications used and frequency of access.

The demographics of the users also help in identifying detailed patterns of each group. Although this study is among the first recent studies to attempt to relate the demographics of users in each group, the user interviews show that the demographic relationships found from the statistical analysis are accurate.

When compared to the previous literature, there is a mixture of different types of users in any given group, and some of them are redundant between groups. The major differences, as shown in Table 16, are the following:

Table 16: Comparison of user types, variety of use, and frequency of use between the past and current studies

\begin{tabular}{|c|c|c|}
\hline User types defined & Previous literature & Current Findings \\
\hline Non-users & $\begin{array}{l}\text { Non-users of the media investigated and the largest } \\
\text { of all user types in representative studies. }\end{array}$ & Smallest group of user types. \\
\hline Sporadics & $\begin{array}{l}\text { Identified in } 20 \text { studies. One of the most evident } \\
\text { user types. Low use, Low variety. }\end{array}$ & Not significant in this study. \\
\hline Debaters & $\begin{array}{l}\text { Bloggers and debaters in social networks. This type } \\
\text { of user is the up and coming user type. } \\
\text { Medium use, medium variety. }\end{array}$ & Not significant in this study. \\
\hline $\begin{array}{l}\text { Entertainment } \\
\text { users }\end{array}$ & $\begin{array}{l}\text { Identified in ten studies. Probably an up and coming } \\
\text { user type because of the high increase in gaming. } \\
\text { Medium use, medium variety. }\end{array}$ & $\begin{array}{l}\text { Found in all groups of users, mostly from } \\
\text { social networks, not from gaming as } \\
\text { predicted in the previous literature. } \\
\text { High use, low variety, mostly from social } \\
\text { networks and YouTube. }\end{array}$ \\
\hline Socializers & $\begin{array}{l}\text { Identified in nine studies out of } 20 \text {. An increasing } \\
\text { user type because of the advent of social media } \\
\text { applications. } \\
\text { Medium use, medium variety. }\end{array}$ & $\begin{array}{l}\text { Found in all groups of users, mostly from } \\
\text { social networks and short messaging } \\
\text { services. } \\
\text { Very high use, low variety. }\end{array}$ \\
\hline Lurkers & $\begin{array}{l}\text { Only identified in five studies, but account for the } \\
\text { biggest user type in social media. They use the } \\
\text { media mainly for lurking, time-killing and/or window } \\
\text { shopping. } \\
\text { Medium use, low variety. }\end{array}$ & $\begin{array}{l}\text { Found in all groups of users, mostly from } \\
\text { social networks, using social networks as } \\
\text { time-killing or everyday routines, not as much } \\
\text { for window shopping. } \\
\text { High use, medium variety. }\end{array}$ \\
\hline Instrumental users & $\begin{array}{l}\text { Identified in } 16 \text { studies. Is a quite common user type } \\
\text { related to media in general and the Internet in } \\
\text { particular. } \\
\text { Medium use, medium variety. }\end{array}$ & $\begin{array}{l}\text { Found in all groups of users, mostly from the } \\
\text { use of Internet banking and information } \\
\text { finding. } \\
\text { High use, medium variety. }\end{array}$ \\
\hline Advanced users & $\begin{array}{l}\text { Identified in } 20 \text { studies. } \\
\text { High use, high variety. }\end{array}$ & $\begin{array}{l}\text { Found in only one group of users, the rarely- } \\
\text { online but try-it-all group. } \\
\text { Low use, high variety. }\end{array}$ \\
\hline
\end{tabular}


Table 14 shows the changes in categories of Internet users and new dimensions of users. Most of the new findings are different from what was found or predicted in previous studies.

It should be noted with caution, however, that the analysis conducted in this paper proved only that there have been changes in Internet user typologies and suggests new ways to categorize them. It does not argue and it is not the objective of this research to show that Internet usage as a whole has changed. Internet usage will still grow, and it is likely that more applications will be offered to users. One can expect to see Internet applications grow on as many technology platforms as they become available, and the behavior of users will be one important factor determining Internet usage in the future.

\section{Conclusion}

This research accomplishes its two objectives. First, it shows that the earlier versions of Internet user typology and their categorization techniques can no longer be used to categorize users, at least in this case study. Therefore, it uses current usage patterns and frequency to categorize users into different clusters and relates the new Internet user groups with demographic data, which is a different technique from that used in the previous literature. Second, it presents a new Internet user typography, which includes a new group, the self-satisficing group, named after the related "satisficing economic concept.

What is found to be consistent with the previous literature is that there is still a group of non-users, but it represents a much lower proportion than in the past. This is true even when comparing the numbers of non-users in developed countries with those in the developing country of Thailand, which is the case study. The case study country still has a lower percentage of non-users.

A few issues are contradictory to the previous literature and expert interviews. First, it was found that current Internet users use several applications and therefore represent a mixture of several types of users that appeared in the previous literature. Therefore, the previous techniques that use the purposes and usage of activities to categorize Internet users are no longer sufficient. Actual usage and frequency of usage and demographic data are used to categorize the user types instead. Second, the Internet user typology has changed from purposed and activity-based to multi-purposed and frequency-based.

Additionally, this research presents a new Internet user typography as a result of using new measures and techniques to categorize the users.

The new finding in this research is the group of users labelled as the self-satisficing group, consisting of three subgroups as presented in the previous section. This self-satisficing group represents the new generation of users who use and access the applications that they deem to suffice and satisfy their needs. They do not care whether the number of applications is optimum or their usage is too much or too little. They are pleased with what they have and act based on their own wills.

\subsection{Implications}

Implications for academicians from this study include the fact that, in Thailand, there have been changes in the patterns of usage of Internet users. The analysis and typology results in this study are applicable only to Thailand at this stage. However, the research notes that there is a need to develop a new methodology for grouping or categorizing Internet users. The methodology proposed in this research is simple yet effective to categorize users into different groups. A new methodology to look into different types of users would be welcome in this research area. It should be noted that the results of this research are applicable to the case of Thailand and have not been generalized elsewhere. Research in other countries is needed to generalize and test the consistency of the results and the methodology that this study offers.

In Thailand and in countries in the region with similar Internet user profiles, broad implications for practitioners from this study are that Internet users' behaviors have changed. The most commonly used and overlooked platform is short messaging services, such as Line or whatsapp, and mobile devices are the easiest platform for users to access. Other implications that may be useful to practitioners stem from the finding that most users spend time on Facebook and Line, as commonly known, but they also surf the web on their own; for example, they still use Google and other applications such as Internet banking. Therefore, it is important that practitioners do not focus on social network usage alone. It is possible to still do business on the web or even as a stand-alone application, whether mobile or Internet, such as mobile banking, as long as the applications serve the specific purposes of the users and the sellers can clearly present the importance of such applications' usage. Here again, it should be noted that, in other countries, similar studies need to be conducted if one wants to obtain specific implications for the countries of interest. 


\subsection{Limitations and Future Study}

Although this study is among the first to cover developing countries, it is focused only in the metropolitan areas. Studies in other countries or in the provincial areas are still needed to test the strength of the proposed methodology and to explore whether the same patterns exist in other developing countries. Future studies could include studies in other developing countries or in provincial areas in Thailand, or they could use new methodologies to look at Internet users as their behavior changes over time.

\section{Website Lists}

[1] Site 1: Forbes Magazine http://www.forbes.com

[2] Site 2: Internet Live Stats Organization http://www.InternetLiveStats.com

\section{References}

[1] S. J. Barnes, H. Bauer, M. Neumann, and F. Huber, Segmenting cyberspace: A customer typology for the Internet, European Journal of Marketing, vol. 41, no. 1, pp. 71-93, 2007.

[2] C. G. Bowker and L. S Star, Sorting Things Out. Classification and its Consequences. London: The MIT Press, 1999.

[3] P. B. Brandtzæg and J. Heim, Social network sites - A typology of users, Journal of Web-Based Communities, vol. 6, no. 3, pp. 231-253, 2010.

[4] P. B. Brandtzæg, J. Heim, B. H. Kaare, T. Endestad, and B. H. L. Torgersen, Gender differences and the digital divide in Norway - Is there really a gendered divide? Presented at the International Conference of Childhoods: Children and youth in Emerging and Transforming Societies, Oslo, Norway, 29 June - 3 July, 2005.

[5] C. G. DeYoung and I. Spence, Profiling information technology users: En route to dynamic personalization, Computers in Human Behavior, vol. 20, no. 1, pp. 55-6, 2004.

[6] L. K. Farquhar and R. Meeds, Types of fantasy sports users and their motivations', Journal of ComputerMediated Communication, vol. 4, no. 12, pp. 1208-1228, 2007.

[7] J. Heim, P. B. Brandtzæg, T. Endestad, B. H. Kaare, and L. Torgersen, Children's usage of media technologies and psychosocial factors, New Media and Society, vol. 9, no. 3, pp. 425-454, 2007.

[8] J. B. Horrigan, A typology of information and communication technology users, Pew Internet and American Life Report, Washington, DC, Pew Internet Report, 2007.

[9] P. E. N. Howard, L. Rainie and S. Jones, Days and nights on the Internet. The impact of a diffusing technology, American Behavioral Scientist, vol. 45, no. 3, pp. 382-404, 2001.

[10] A. L. Jepsen, Information search in virtual communities: Is it replacing use of off-line communication? Journal of Marketing Communications, vol. 12, no. 4, 247-261, 2006.

[11] G. M. Johnson and A. Kulpa, Dimensions of online behavior: Toward a user typology, CyberPsychology and Behavior, vol. 10, no. 6, pp. 773-779, 2007.

[12] U. Johnsson-Smaragdi, Media use styles among the young, in Children and their Changing Media Environment: A European Comparative Study (S. Livingstone and M. Bovill, Eds.). Hillsdale, NJ: Lawrence Erlbaum Associates, 2001, pp. 113-141.

[13] C. Li, J. Bernoff, R. Fiorentino and S. Glass, Social technographics mapping participation in activities forms, Forrester, New York, A Forrester Research Report, 2007.

[14] V. OFCOM, Social Networking. A Quantitative and Qualitative Research Report into Attitudes, Behaviours and Use. London, UK: Office of Communication, 2008.

[15] J. M. Ortega Egea, M. R. Menéndez and M. V. R. González, Diffusion and usage patterns of Internet services in the European Union, informations research, International Electronic Journal, vol. 12, no. 2, p. 302, 2007.

[16] D. F. Roberts, U. G. Foehr, V. J. Rideout, and M. Bordi, Kids and Media in America. New York: Cambridge University Press, 2004.

[17] D. Shah, N. Kwak and R. Holbert, Connecting and 'disconnecting with civic life: Patterns of Internet use and the production of social capital, Political Communication, vol. 18, no. 2, pp. 141-162, 2001.

[18] K. B. Sheehan, Toward a typology of internet users and online privacy concerns, The Information Society, vol. 18, no. 1, pp. 21-32, 2010.

[19] C.-F. Shih and A. Venkatesh, Beyond adoption: Development and application of a use-diffusion model, Journal of Marketing, vol. 68, no.1, pp. 59-72, 2004.

[20] H. A. Simon, Rational choice and the structure of the environment, Psychological Review, vol. 63, no. 2, pp. 129-138, 1956. 


\section{Appendix A: Questionnaire}

\section{Gender}

\begin{tabular}{|l|l|}
\hline Male & 1 \\
\hline Female & 2 \\
\hline
\end{tabular}

\section{Highest Education Level}

\begin{tabular}{|l|l|}
\hline Primary School & 1 \\
\hline High school & 2 \\
\hline Diploma & 3 \\
\hline Undergraduate & 4 \\
\hline Graduate & 5 \\
\hline
\end{tabular}

\section{Occupation}

\begin{tabular}{|l|l|}
\hline Student & 1 \\
\hline Government officer & 2 \\
\hline Private sector & 3 \\
\hline Business owner & 4 \\
\hline Home caretaker & 5 \\
\hline Others .............. & 9 \\
\hline
\end{tabular}

\section{Internet Users}

Q1. Do you use the Internet?

\begin{tabular}{|l|l|l|}
\hline Yes & 1 & (Continue the interview) \\
\hline No & 2 & (Record and exit the interview) \\
\hline
\end{tabular}

\section{Your Income}

\begin{tabular}{|l|l|}
\hline Less than 10,000 THB & 1 \\
\hline $10,001-20,000$ THB & 2 \\
\hline $20,001-30,000$ THB & 3 \\
\hline $30,001-40,000$ THB & 4 \\
\hline $40,001-50,000$ THB & 5 \\
\hline $50,001-60,000$ THB & 6 \\
\hline $60,001-70,000$ THB & 7 \\
\hline More than 70,000 THB & 8 \\
\hline
\end{tabular}


Q2. What are the frequency of you using the following applications?

\begin{tabular}{|c|c|c|c|c|c|}
\hline \multirow[t]{2}{*}{ Application } & \multicolumn{5}{|c|}{ Frequency of Use } \\
\hline & $\begin{array}{l}\text { More than } \\
\text { once a day }\end{array}$ & Everyday & $\begin{array}{l}4-6 \\
\text { times } \\
\text { per } \\
\text { week }\end{array}$ & $\begin{array}{l}\text { 1-3 times } \\
\text { per week }\end{array}$ & Never \\
\hline Internet banking or mobile banking & 1 & 2 & 3 & 4 & 99 \\
\hline Video and music download & 1 & 2 & 3 & 4 & 99 \\
\hline $\begin{array}{l}\text { Watch videos on YouTube without } \\
\text { downloading }\end{array}$ & 1 & 2 & 3 & 4 & 99 \\
\hline Facebook & 1 & 2 & 3 & 4 & 99 \\
\hline Twitter & 1 & 2 & 3 & 4 & 99 \\
\hline Line and whatsapp & 1 & 2 & 3 & 4 & 99 \\
\hline Online gaming & 1 & 2 & 3 & 4 & 99 \\
\hline Use Internet directly through URLs & 1 & 2 & 3 & 4 & 99 \\
\hline Advances usage or blogging & 1 & 2 & 3 & 4 & 99 \\
\hline
\end{tabular}

Q3. What is the average time that you spend on the following applications?

\begin{tabular}{|l|c|c|c|c|c|}
\hline Application & $\begin{array}{c}\text { More than 2 } \\
\text { hours per } \\
\text { one use }\end{array}$ & $\begin{array}{c}\mathbf{1 - 2} \text { hours } \\
\text { per one } \\
\text { use }\end{array}$ & $\begin{array}{c}\text { 31-60 } \\
\text { minutes } \\
\text { per one } \\
\text { use }\end{array}$ & $\begin{array}{c}\mathbf{1 - 3 0} \\
\text { minutes } \\
\text { per one } \\
\text { use }\end{array}$ & $\begin{array}{c}\text { Do not } \\
\text { use at } \\
\text { all }\end{array}$ \\
\hline Internet banking or mobile banking & 1 & 2 & 3 & 4 & 99 \\
\hline Video and music download & 1 & 2 & 3 & 4 & 99 \\
\hline $\begin{array}{l}\text { Watch videos on YouTube without } \\
\text { downloading }\end{array}$ & 1 & 2 & 3 & 4 & 99 \\
\hline Facebook & 1 & 2 & 3 & 4 & 99 \\
\hline Twitter & 1 & 2 & 3 & 4 & 99 \\
\hline Line and whatsapp & 1 & 2 & 3 & 4 & 99 \\
\hline Online gaming & 1 & 2 & 3 & 4 & 99 \\
\hline Use Internet directly through URLs & 1 & 2 & 3 & 4 & 99 \\
\hline Advances usage or blogging & & 2 & & 4 \\
\hline
\end{tabular}


Q4. What is the frequency of the following activities in a week?

\begin{tabular}{|c|c|c|c|c|c|}
\hline \multirow{2}{*}{ Internet / mobile banking } & \multicolumn{2}{|c|}{ 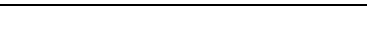 } & \multirow{2}{*}{$\begin{array}{l}\text { 4-6 times } \\
\text { per week }\end{array}$} & \multirow[b]{2}{*}{$\begin{array}{l}\text { 1-3 times } \\
\text { per week }\end{array}$} & \multirow[b]{2}{*}{ Never } \\
\hline & $\begin{array}{l}\text { More than } \\
\text { once a day }\end{array}$ & Everyday & & & \\
\hline Balance checking & 1 & 2 & 3 & 4 & 99 \\
\hline Money transfer & 1 & 2 & 3 & 4 & 99 \\
\hline Pay for utilities & 1 & 2 & 3 & 4 & 99 \\
\hline Refill the phone balance & 1 & 2 & 3 & 4 & 99 \\
\hline Stock trading & 1 & 2 & 3 & 4 & 99 \\
\hline 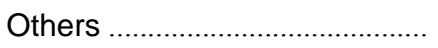 & 1 & 2 & 3 & 4 & 99 \\
\hline
\end{tabular}

Q5. What is the frequency of the following activities in a week?

\begin{tabular}{|l|l|l|l|l|l|}
\hline Video / YouTube & \multicolumn{3}{|c|}{} & \multicolumn{2}{|c|}{ Never } \\
\cline { 2 - 6 } & $\begin{array}{l}\text { More than } \\
\text { once a day }\end{array}$ & Everyday & $\begin{array}{l}4-6 \text { times } \\
\text { per week }\end{array}$ & $\begin{array}{l}1-3 \text { times } \\
\text { per week }\end{array}$ & \\
\hline $\begin{array}{l}\text { 1. Watch videos for entertainment as } \\
\text { suggested by the programs and not } \\
\text { giving comments }\end{array}$ & 1 & 2 & 3 & 4 & 99 \\
\hline $\begin{array}{l}2 \text { Search and watch videos for non- } \\
\text { entertainment purposes }\end{array}$ & 1 & 2 & 3 & 4 & 99 \\
\hline $\begin{array}{l}\text { 3. Upload videos onto video } \\
\text { platforms, such as YouTube }\end{array}$ & 1 & & 3 & 4 & 99 \\
\hline
\end{tabular}

Q6. What is the frequency of the following activities in a week?

\begin{tabular}{|c|c|c|c|c|c|}
\hline Facebook & $\begin{array}{l}\text { More than } \\
\text { once a day }\end{array}$ & Everyday & $\begin{array}{l}4-6 \text { times } \\
\text { per week }\end{array}$ & $\begin{array}{l}\text { 1-3 times } \\
\text { per week }\end{array}$ & Never \\
\hline $\begin{array}{l}\text { 1. Use Facebook as a routine task in } \\
\text { everyday life }\end{array}$ & 1 & 2 & 3 & 4 & 99 \\
\hline 2. Use Facebook to kill time & 1 & 2 & 3 & 4 & 99 \\
\hline $\begin{array}{l}\text { 3.Read newsfeed for non- } \\
\text { entertainment purposes, such as } \\
\text { news update }\end{array}$ & 1 & 2 & 3 & 4 & 99 \\
\hline $\begin{array}{l}\text { 4. Read newsfeed for entertainment } \\
\text { purposes }\end{array}$ & 1 & 2 & 3 & 4 & 99 \\
\hline 5. Post or share status & 1 & 2 & 3 & 4 & 99 \\
\hline $\begin{array}{l}\text { 6. Use Facebook for socializing with } \\
\text { Friends }\end{array}$ & 1 & 2 & 3 & 4 & 99 \\
\hline $\begin{array}{l}\text { 7.Use Facebook to participate in } \\
\text { your community }\end{array}$ & 1 & 2 & 3 & 4 & 99 \\
\hline 8.Use Facebook for shopping & 1 & 2 & 3 & 4 & 99 \\
\hline
\end{tabular}


Q7. What is the frequency of the following activities in a week?

\begin{tabular}{|l|l|l|l|l|l|}
\hline Twitter & $\begin{array}{l}\text { More than } \\
\text { once a day }\end{array}$ & Everyday & $\begin{array}{l}4-6 \text { times } \\
\text { per week }\end{array}$ & $\begin{array}{l}1-3 \text { times } \\
\text { per week }\end{array}$ & Never \\
\hline 1.Read Tweets to kill time & 1 & 2 & 3 & 4 & 99 \\
\hline $\begin{array}{l}\text { 2.Read Tweets to keep up with your } \\
\text { friends }\end{array}$ & 1 & 2 & 3 & 4 & 99 \\
\hline $\begin{array}{l}\text { 3. Read Tweets for non- } \\
\text { entertainment purposes, such as } \\
\text { news update }\end{array}$ & 1 & 2 & 3 & 4 & 99 \\
\hline 4.Tweet or retweet the messages & 1 & 2 & 3 & 4 & 99 \\
\hline
\end{tabular}

Q8. What is the frequency of the following activities in a week?

\begin{tabular}{|l|l|l|l|l|l|}
\hline Line, WhatsApp & $\begin{array}{l}\text { More than } \\
\text { once a day }\end{array}$ & Everyday & $\begin{array}{l}4-6 \text { times } \\
\text { per week }\end{array}$ & $\begin{array}{l}1-3 \text { times } \\
\text { per week }\end{array}$ & Never \\
\hline $\begin{array}{l}\text { 1.Use Line/Whatsapp to socialize } \\
\text { with your friends }\end{array}$ & 1 & 2 & 3 & 4 & 99 \\
\hline 2.Read feeds on Timeline & 1 & 2 & 3 & 4 & 99 \\
\hline 3.Use Line/whatsapp for shopping & 1 & 2 & 3 & 4 & 99 \\
\hline
\end{tabular}

Q9. Do you play online games to kill time?

\begin{tabular}{|l|l|}
\hline Yes & 1 \\
\hline No & 2 \\
\hline
\end{tabular}

Q10. You play online games because you are serious about it and you have friends playing online.

\begin{tabular}{|l|l|}
\hline Yes & 1 \\
\hline No & 2 \\
\hline
\end{tabular}

Q11. What is the frequency of the following activities in a week?

\begin{tabular}{|l|l|l|l|l|l|}
\hline $\begin{array}{l}\text { General Internet (without social } \\
\text { network) }\end{array}$ & $\begin{array}{l}\text { More than } \\
\text { once a day }\end{array}$ & Everyday & $\begin{array}{l}4-6 \text { times } \\
\text { per week }\end{array}$ & $\begin{array}{l}1-3 \text { times } \\
\text { per week }\end{array}$ & Never \\
\hline 1. To compare the price of products & 1 & 2 & 3 & 4 & 99 \\
\hline $\begin{array}{l}\text { 2. Use to find promotions and } \\
\text { discounts }\end{array}$ & 1 & 2 & 3 & 4 & 99 \\
\hline $\begin{array}{l}\text { 3. Use to find new knowledge or } \\
\text { information }\end{array}$ & 1 & 2 & 3 & 4 & 99 \\
\hline $\begin{array}{l}\text { 4. Use to express your opinions on } \\
\text { web boards or online community }\end{array}$ & 1 & 2 & 3 & 4 & 99 \\
\hline
\end{tabular}


Journal of Theoretical and Applied Electronic Commerce Research

ISSN 0718-1876 Electronic Version

VOL 13 / ISSUE 2 / MAY 2018 / 58-79

(C) 2018 Universidad de Talca - Chile
This paper is available online at www.jtaer.com

DOI: $10.4067 / S 0718-18762018000200106$

Q12. What is the frequency of the following activities in a week?

\begin{tabular}{|l|l|l|l|l|l|}
\hline Advanced activities & $\begin{array}{l}\text { More than } \\
\text { once a day }\end{array}$ & Everyday & $\begin{array}{l}4-6 \text { times } \\
\text { per week }\end{array}$ & $\begin{array}{l}1-3 \text { times } \\
\text { per week }\end{array}$ & Never \\
\hline 1.Blogging & 1 & 2 & 3 & 4 & 99 \\
\hline 2.Programming & 1 & 2 & 3 & 4 & 99 \\
\hline
\end{tabular}

